\title{
EPISTEMOLOGIA DE TERRA-PÁTRIA PARA UMA NOVA CIDADANIA PLANETÁRIA
}

\author{
EPISTEMOLOGY OF THE HOMELAND EARTH FOR A NEW PLANETARY \\ CITIZENSHIP
}

\author{
EPISTEMOLOGÍA DE TIERRA PATRIA PARA UNA NUEVA CIUDADANÍA \\ PLANETARIA
}

\author{
Maria Cândida Moraes \\ Doutora em Educação e Currículo, pela PUC/SP. \\ Pesquisadora permanente do GEPEC - Grupo de Estudos e Pesquisa em Complexidade/CNPq. \\ Universidade Metodista de São Paulo - UMESP \\ mariacandidam4@gmail.com \\ (iD) Izabel Petraglia \\ Doutora em Educação pela USP \\ Pós-doutorado pelo Centre Edgar Morin, da EHESS/CNRS, Paris. \\ Professora titular do PPGE da Universidade Metodista de São Paulo. \\ Líder do GEPEC/CNPq \\ izabelpetraglia@terra.com.br
}

\begin{abstract}
Resumo: Este artigo tem por objetivo refletir sobre o conceito de Terra-Pátria, a partir do livro homônimo, de Edgar Morin e Anne-Brigitte Kern, considerando a epistemologia da complexidade, que promove a mudança de pensamento - do linear ao complexo - para a reintegração de cultura científica e cultura humanística. Essa perspectiva implica uma nova visão de mundo, um novo pacto ético civilizatório, fundado não apenas na razão ilustrada, mas também na sensibilidade humana e na inteligência emocional que se expressam através do cuidado, da solidariedade, da compreensão e da responsabilidade ecológica e social. Por meio da metodologia de pesquisa bibliográfica, articulamos ainda a obra Terra-Pátria às recomendações da Carta da Terra pela via do desenvolvimento sustentável, que nos leva à construção de uma nova cidadania planetária. Consideramos aqui as seguintes indagações norteadoras: Quais são os fundamentos teóricos presentes nesta obra e que podem ser considerados como bases estruturantes de uma teoria pedagógica capaz de iluminar a educação em direção a essa nova cosmovisão? De que forma a epistemologia presente na obra Terra-Pátria pode inspirar ou orientar a ação pedagógica em direção à reforma do pensamento e das instituições educativas? Concluímos com o reconhecimento de que os operadores cognitivos do pensamento complexo são mecanismos geradores dessa epistemologia e que práticas pedagógicas transdisciplinares são fundamentais à melhor compreensão da realidade.
\end{abstract}

Palavras-chave: cidadania planetária; epistemologia; pensamento complexo; Terra-Pátria.

Abstract: This article aims to reflect on the concept of Homeland Earth, from the eponymous book by Edgar Morin and Anne-Brigitte Kern, considering the epistemology of the complexity, which brings about a change in thinking - from linear to complex - for the reintegration of scientific culture and humanistic culture. This perspective points to a new worldview, a new ethical pact for civilization, founded not only on illustrated reason, but also on human sensibility and emotional intelligence that are expressed through care, solidarity, understanding, and ecological and social responsibility. Through the methodology of bibliographic research, we also link up the Homeland Earth work with the recommendations of the Earth Charter through sustainable development, which leads us to the creation of a new planetary citizenship. We consider the following guiding questions: What are the theoretical foundations present in this work that can be considered as the underlying bases for a pedagogical theory capable of enlightening education and moving it towards this new cosmovision? How can the epistemology present in Homeland Earth inspire or guide pedagogical action towards a reform of thinking and educational institutions? We conclude by recognizing that the cognitive operators of complex thinking are mechanisms that generate this epistemology and that transdisciplinary pedagogical practices are fundamental for a better understanding of reality.

Keywords: planetary citizenship; epistemology; complex thinking; Homeland Earth.

Resumen: Este artículo tiene por objeto reflexionar sobre el concepto de Tierra Patria, a partir del libro homónimo, de Edgar Morin y Anne-Brigitte Kern, considerando la epistemología de la complejidad que promueve el cambio de pensamiento - de lo lineal a lo complejo- en pro de la reintegración de cultura científica y cultura humanística. Esa perspectiva implica una nueva visión de mundo, un nuevo pacto ético civilizatorio fundamentado no solo en la razón ilustrada, sino también en la sensibilidad humana y la inteligencia emocional que se expresan por medio del cuidado, la solidaridad, la comprensión y la responsabilidad ecológica y social. Por medio de la metodología de investigación bibliográfica, articulamos también la obra Tierra Patria con las recomendaciones de la Carta de la Tierra por la vía del desarrollo sostenible que nos conduce a la construcción de una nueva ciudadanía planetaria. Aquí nos guiamos por las siguientes indagaciones: ¿cuáles son los fundamentos teóricos presentes en esta obra que pueden considerarse bases estructurantes de una teoría pedagógica capaz de iluminar la educación en dirección a esa nueva cosmovisión?, ¿de qué forma la epistemología presente en la obra Tierra Patria puede inspirar u orientar la acción pedagógica en dirección a la reforma del pensamiento y de las instituciones educativas? Concluimos con el reconocimiento de que los operadores cognitivos del pensamiento complejo son mecanismos generadores de esa epistemología y de que prácticas pedagógicas transdisciplinarias son fundamentales para comprender mejor la realidad.

Palabras clave: ciudadanía planetaria; epistemología; pensamiento complejo; Tierra Patria.

Para citar - (ABNT NBR 6023:2018)

MORAES, Maria Cândida, PETRAGLIA, Izabel. Epistemologia de Terra-Pátria para uma nova cidadania planetária. Eccos - Revista Científica, São Paulo, n. 57, p. 1-15, e20270, abr./jun. 2021. Disponível em: https://doi.org/10.5585/eccos.n57.20270. 


\section{Introdução}

Estamos diante de um momento crítico na história da Terra, numa época em que a humanidade deve escolher o seu futuro. À medida que o mundo se torna cada vez mais interdependente e frágil, o futuro reserva, ao mesmo tempo, grande perigo e grande esperança. Para seguir adiante, devemos reconhecer que, no meio de uma magnífica diversidade de culturas e formas de vida, somos uma família humana e uma comunidade terrestre com um destino comum. Devemos nos juntar para gerar uma sociedade sustentável global fundada no respeito pela natureza, nos direitos humanos universais, na justiça econômica e numa cultura de paz. Para chegar a este propósito, é imperativo que nós, os povos da Terra, declaremos nossa responsabilidade uns para com os outros, com a grande comunidade de vida e com as futuras gerações.(Carta da Terra, Preâmbulo). (BRASIL, 2021a).

De acordo com Morine Kern, Terra-Pátria é a nossa casa comum, a mesma comunidade de origem e de destino. Refere-se ao lugar dos sonhos possíveis de realização humana de uma sociedade-mundo fraterna, solidária, sustentável e responsável. Assumir nossa cidadania terrestre é assumir nossa comunidade de destino. Para os autores, pertencemos à Terra que nos pertence, em função do nosso enraizamento no Cosmo. Terra, aqui compreendida como totalidade complexa, envolvendo as dimensões física, biológica e antropológica, onde a vida é uma emergência da história da Terra e o homem é uma emergência da história da vida terrestre (MORIN; KERN, 2001,2011).

Por outro lado, este conceito se aproximado que foi estabelecido no documento Carta da Terra, conforme excerto em epígrafe, à medida em que nos propõe uma ética global pautada no respeito às diversas formas de vida e à necessidade de se viver com compreensão, compaixão e amor. O conceito Terra-Pátria também traz consigo a sacralidade da vida, a biodiversidade e a interdependência, advertindo-nos sobre a impossibilidade de se resolver qualquer problema sem pensar nos demais problemas, já que tudo e todos se influenciam mutuamente.

O conceito Terra-Pátria também se aproxima das proposições e recomendações estabelecidas pela Carta da Terra (BRASIL, 2021) pela via do desenvolvimento sustentável, associada à necessidade de se construir uma consciência mundial de natureza política ao redor dos valores relacionados a uma nova cidadania planetária, pautada na sustentabilidade e no humanismo solidário. Tanto um documento como o outro são uníssonos em suas advertências comuns a respeito da insustentabilidade das atuais formas de se viver/conviver, do ritmo desenfreado em que utilizamos os recursos essenciais do Planeta, da degradação da biodiversidade e das consequências do efeito estufa na atmosfera, além de destacar o papel da mão humana que envenena solos, mares, rios e o ar que se respira. Como humanidade, produzimos todo tipo de contaminantes e o planeta já não consegue mais digeri-los.

Em realidade, somos filhos da Terra e do Cosmo e nos esquecemos disto. Trazemos em cada um de nós o mundo físico, biológico, social, cultural e espiritual que une tudo e a todos. 
Esta consciência de nossa materialidade comum exige uma mudança imediata em nossa visão de mundo, no sentido de superar o reducionismo, a fragmentação e a superatividade propugnadas pela ciência tradicional, com seus valores insustentáveis, nutridores de uma ética incompatível com as demandas atuais e cujas consequências destrutivas e catastróficas para o planeta são absolutamente inimagináveis.

Sem a mudança paradigmática na matriz científica que ainda predomina na sociedade humana, dificilmente conseguiremos promover o diálogo transdisciplinar entre os especialistas das diversas áreas do conhecimento, na busca de soluções aos graves problemas ecológicos, sociais, culturais, econômicos e sanitários que atualmente enfrentamos.

Para mudar o pensamento humano em direção a essa visão de mundo proposta tanto pela obra Terra-Pátria (MORIN; KERN, 2001,2011) quanto pela Carta da Terra (BRASIL, 2021a), é preciso uma nova cosmovisão pautada em novos fundamentos da ciência, para que possamos realizar um novo pacto ético civilizatório, fundado não apenas na razão ilustrada, mas também na sensibilidade humana e na inteligência emocional que se expressam através do cuidado, da solidariedade, da compreensão e da responsabilidade ecológica e social.

Assim, tanto o conceito Terra-Pátria como as recomendações da Carta da Terra agregam essa outra cosmovisão, que traz consigo uma epistemologia de natureza complexa e que nos leva à construção de uma nova cidadania planetária. Uma cidadania capaz de garantir o direito à vida a todos os seres viventes e a busca pelo desenvolvimento sustentável, visando a construção de um Planeta ecológica e socialmente mais justo, solidário, pacífico e acolhedor. Um novo humanismo, regenerado, porque se nutre de fontes antropológicas da ética (MORIN, 2020).

A concepção rejuvenescedora da ideia desse "novo" nos remete ao que há de melhor, mais importante e necessário para este momento civilizatório que estamos vivendo, o que nos leva a concordar com Morine Kern(2001,2011), ao explicarem que essa perspectiva valoriza o que é durável e consistente, ainda que incerto e passível de movimento e processos de regeneração. Assim, a ideia de uma nova cidadania planetária deve ser capaz de garantir o direito terrestre a todos os seres viventes.

Desta forma e a partir da metodologia de pesquisa bibliográfica realizada, pretendemos, através deste artigo, revisitaras ideias de Edgar Morin, especialmente expressas no livro, sempre atual, Terra-Pátria, de Morin e Kern $(2001,2011)$. Para tanto, levaremos em consideração as seguintes indagações norteadoras de nossos questionamentos: Quais são os fundamentos teóricos presentes nesta obra e que podem ser considerados como bases estruturantes de uma teoria pedagógica capaz de iluminar a educação em direção a essa nova cosmovisão? De que 
forma a epistemologia presente na obra Terra-Pátria pode inspirar ou orientar a ação pedagógica em direção à reforma do pensamento e das instituições educativas?

Essas questões nos inspiração diálogo com temas pungentes da atualidade presentes na Carta da Terra e que estimulam a busca pelo desenvolvimento sustentável também propugnado pela Agenda 2030: Objetivos do desenvolvimento sustentável, das Nações Unidas (BRASIL, 2021b).Então, refletiremos sobre a epistemologia da complexidade implícita na obra Terra-

Pátria e que nos remete às práticas pedagógicas transdisciplinares que consideram a importância da reforma do pensamento humano a partir do pensamento complexo, que é crítico, criativo, emancipador e humanizador. Destacaremos, também, os princípios da complexidade, como operadores cognitivos nutridores de uma pedagogia integral transdisciplinar e identificaremos as perspectivas epistemológicas da complexidade presentes no conceito Terra-Pátria e que fundamentam a mudança paradigmática pretendida e a busca de novos horizontes civilizatórios para o bem-viver/conviver a partir de uma nova educação.

\section{Epistemologia da complexidade presente na obra Terra-Pátria}

Para Mario Bunge (1977), a epistemologia é um ramo da filosofia que estuda o conhecimento científico. "Ela se ocupa de problemas filosóficos que se apresentam no curso da investigação científica ou na reflexão a respeito dos problemas, métodos e teorias da ciência" (BUNGE, 1977, p. 29). Em outra obra, Bunge (1980, p. 182) explica que

[...] a epistemologia ou, a filosofia da ciência, é aquela que investiga a natureza do conhecimento científico e tecnológico [...] a epistemologia é a que se ocupa das questões teóricas básicas concernentes à ciência e à tecnologia. A epistemologia, em resumo, é o eixo da ciência da ciência.

Por sua vez, Ernst von Glasersfeld (1994, p. 37), em seu artigo Introdução ao construtivismo radical, entende que "[...] a epistemologia se converte no estudo de como a inteligência opera, da maneira e da forma como o intelecto faz uso para construir um mundo aparentemente regular, a partir do fluir de sua experiência". Ele chama de "operar" à atividade que constrói conhecimento.

E como será que a inteligência humana opera a partir de uma epistemologia da complexidade? Sabemos que a complexidade, em sua dimensão lógica, implica uma nova epistemologia, uma nova explicação da realidade ou uma nova narrativa sobre o conhecimento do real. Uma narrativa que ajuda a melhor compreender a dinâmica da vida, incluindo aqui a realidade humana, a realidade social, ecológica e planetária. Ela traz consigo um modo diferente 
de operar a racionalidade, a partir de uma outra lógica, nutrida por um conjunto de princípios e regras que guiam a razão humana, associada ao pensamento complexo.

Isso porque, ao trabalhar com o que acontece nos diversos níveis fenomenológicos ou níveis de materialidade dos objetos, muitas vezes nos deparamos com fatos, fenômenos e eventos que se apresentam no mundo fenomênico de maneira paradoxal, oposta, difícil de ser compreendida a partir da lógica tradicional. Daí a necessidade de outras ferramentas intelectuais que nos ajudem a compreender a complexidade intrínseca a esses processos, ou seja, a complexidade que dialoga com a simplicidade, com o equilíbrio que está sempre em movimento, com a desordem e a ordem presentes no seio de uma organização qualquer. Se não soubermos dialogar com as incertezas, as emergências e o acaso, perceber a dinâmica intrínseca às "ações ecologizadas" que disparam seus efeitos por direções imprevistas anteriormente, como podemos conhecer essa realidade mutante, difusa, incerta e indeterminada que se manifesta no mundo fenomênico? Uma realidade que é multidimensional, estável e ao mesmo tempo instável, contínua e descontínua em sua dinâmica operacional. Será que o paradigma tradicional da ciência, com sua epistemologia que elimina as contradições, as incertezas, as ambiguidades e a imprevisibilidade presentes nas relações sujeito e objeto, dá conta de explicar a dinâmica operativa desse mundo fenomênico com o qual vivemos e convivemos diariamente?

Sabemos que não! Os avanços da ciência do século XX mudaram as perspectivas epistemológicas do sujeito pensante, do observador científico, passando a explicar as relações entre o mundo físico, biológico, antropológico e social de outra maneira, na tentativa de assegurar a comunicação entre esses diversos níveis fenomenológicos existentes. E para conhecer essa realidade complexa, fruto de uma engenharia ontologicamente complexa e enredada, produto de interações, conexões e interdependências ocorrentes em todos os domínios da vida, é preciso novas ferramentas intelectuais compatíveis com a dinâmica do conhecimento a ser processado. Novas ferramentas associadas às novas linguagens que ajudem a evitar o reducionismo, o determinismo, a fragmentação do real, a separação sujeito/objeto e a anulação do sujeito pensante. Linguagens nutridas por uma epistemologia aberta ao movimento da vida, às incertezas, às emergências, à dialógica, à recursividade, aos processos de auto-ecoorganização e à criatividade intrínseca à natureza da matéria e que resgatam o sujeito esquecido pela ciência moderna. Tais princípios estão presentes no coração dos processos vitais de natureza complexa.

Mas, para operar a partir de uma epistemologia da complexidade, é preciso promover a abertura de nossas gaiolas epistemológicas, como diria nosso querido amigo Ubiratan D’Ambrósio, para que possamos resgatar o sujeito e a subjetividade humana na ciência e nas 
práticas educativas e melhor compreender a realidade da matéria. Resgatá-lo e, ao mesmo tempo, empoderá-lo como autor de sua história e coautor de construções coletivas, como observador participante e sensível, construtor do conhecimento e da realidade. Um sujeito já não mais solitário, egoísta e prepotente, mas pensante, solidário, mestiço, cuidadoso, proativo, consciente de seu inacabamento e da provisoriedade de sua história, de seus talentos e potencialidades.

\section{Operadores cognitivos para um pensar complexo}

Ao falamos sobre os "operadores cognitivos para um pensar complexo", em realidade, estamos nos referindo a um conjunto de princípios inovadores estabelecidos por Edgar Morin, que nos ajudam a compreender o real, a dialogar com uma realidade que é multidimensional, constituída por vários níveis fenomenológicos. Eles ampliam nossa capacidade de percepção e de diálogo, e nos ajudam a colocar em prática essa racionalidade complexa que religa o conhecimento do todo ao conhecimento das partes, o que, em última instância, promove a reforma do pensamento e das ações dele consequentes.

Quais seriam, então, esses princípios ou categorias que nos ajudam a pensar o complexo e que dialogam com as estratégias do pensamento e da ação humana ao romperem com a ditadura do paradigma da simplificação, da fragmentação e do reducionismo? São as ferramentas intelectuais desenvolvidas por Edgar Morin, reconhecidas como operadores cognitivos para um pensar complexo e que nos ajudam a conhecer e a melhor compreender a complexidade do real, a colocar em prática outro tipo de lógica, de racionalidade e de pensamento mais condizente com a evolução da ciência e mais coerente com a dinâmica complexa da natureza e da vida. São princípios de inteligibilidade, organizadores de nossas operações mentais, profundamente articulados entre si, de maneira complementar e interdependente e, ao mesmo tempo, coerentes com os processos de complexificação crescente não apenas do conhecimento, mas do que acontece a partir da tessitura comum existente entre os diversos níveis fenomenológicos constitutivos da realidade da matéria.

Assim, de maneira resumida, apresentamos, a seguir, os operadores cognitivos descritos por Edgar Morin (MORIN; LE MOIGNE, 2000, p. 209-212):

1) Princípio sistêmico ou organizacional: liga a compreensão do todo à compreensão das partes. Indica que "o todo é mais do que a soma das partes”. Se parasse aqui, seria uma visão reducionista da realidade, mas os autores acrescentam: "o todo é também menos que a soma das partes”. 
2) Princípio hologramático: evoca a imagem do holograma, como em um caleidoscópio, em que cada pequenina parte pode conter "a quase totalidade da informação do objeto que ele representa". O todo está na parte, assim como a parte está no todo.

3) Princípio do círculo retroativo: elimina a ideia da causalidade linear, em que a causa age sobre o efeito e este sobre aquele. Ou seja, uma ação pode promover outra ação ampliada, que pode promover outra ainda mais e, assim, sucessivamente.

4) Princípio do círculo recursivo:de maneira semelhante ao princípio anterior, os produtos e os efeitos são ao mesmo tempo produtores e causadores. Inspirados pela imagem circular de um espiral, nós podemos dizer que somos produtos e produtores de cultura, simultaneamente.

5) Princípio da auto-eco-organização: autonomia e dependência pressupõem que o ser humano é, ao seu tempo, tanto autônomo quanto dependente de sua cultura, linguagem, comunidade e família. Ele é capaz de se transformar continuamente e, ao fazê-lo, influencia e/ou transforma o seu ecossistema, ao passo que também sofre as suas influências.

6) Princípio dialógico: é o que une noções aparentemente antagônicas e/ou contraditórias. Integra ideias opostas e complementares que não se excluem. É o que explica as contradições que são insuperáveis, promovendo a manutenção do conflito e a não resolução. Por exemplo: vida-morte; sabedoria-loucura.

7) Princípio da reintrodução do conhecimento em todo conhecimento: une o simples ao complexo, reúne e distingue, integra certezas às incertezas, indica que todo o conhecimento é uma interpretação dos fenômenos da realidade. Religa os diversos tipos de pensamentos.

A esses sete princípios acrescentamos um outro também descrito por Edgar Morin (2011) e que se refere à ecologia da ação. Este princípio nos informa que toda ação é sempre uma ação ecologizada, ao entrar no jogo das inter-retroações e não mais nos pertence. Assim, é a partir dessas ações ecologizadas que emergem novas estruturas de pensamento. Um pensamento que passa a ser ecologizado, ou seja, que religa o conhecimento, que conecta os saberes científicos e humanísticos, contextualizando-os e promovendo a ecologia dos saberes.

Todos esses aspectos são de extrema relevância para as propostas educacionais e para a percepção das consequências de nossos pensamentos e ações, tanto no que se refere a nós mesmos como também aos outros e à natureza. Adequadamente trabalhados, eles nos ajudam a 
promover uma nova ecologia da aprendizagem humana, nutrida por uma reforma paradigmática na educação e nas demais instituições sociais, ambientais e culturais das quais fazemos parte.

Esses operadores são, portanto, mecanismos cognitivos geradores de uma epistemologia - a epistemologia da complexidade. Eles fazem com que a complexidade, em sua dimensão lógica e epistemológica, transforme-se em um guia ou princípio regulador do pensamento e da ação humana, independentemente da área de conhecimento trabalhada. Ao serem colocados em prática, esses operadores ajudam a compreender e a materializar a dimensão epistemológica da complexidade nos processos de construção do conhecimento.

O uso dos operadores cognitivos para um pensar complexo é condição fundamental para uma nova racionalidade mais dialógica, intuitiva, criativa, crítica, inovadora, global, aberta; superadora da fragmentação, do reducionismo, a partir de um pensamento dialógico, movido por questionamentos, perguntas e dúvidas. Este tipo de racionalidade complexa está presente na epistemologia da obra Terra-Pátria (MORIN; KERN, 2001,2011)e favorece uma maneira de pensar que une e solidariza o conhecimento fragmentado, que não se fecha no local e no singular, mas que dialoga com o que é global e diverso, com os antagonismos e as contradições.

É uma epistemologia inacabada, desprovida de fundamentos de certeza, em que o conhecimento humano está sempre em contínuo movimento de construção, desconstrução e reconstrução, oque nos ajuda a reformar o pensamento e a transformar as ações humanas ao trazer consigo várias consequências éticas, existenciais e cívicas, presentes também nos processos de construção de um conhecimento que compreende a multidimensionalidade dos fenômenos físicos, biológicos, sociais e culturais. Tal processo supera assim a concepção fragmentadora, linear e determinista da realidade e do conhecimento da Ciência Moderna.

\section{Por uma nova antropologia, axiologia e ética planetária}

A partir das explicações anteriores, perguntamos: quais são as perspectivas epistemológicas da complexidade presentes no conceito Terra-Pátria, capazes de fundamentar uma nova antropologia, uma axiologia e uma ética planetária? Tais perspectivas são capazes de civilizar as relações humanas e despertar uma nova consciência ética e política que aponte para o sentido da unidade/diversidade humana e de pertencimento a uma comunidade de origem e de destino?

Uma perspectiva teórica é uma postura filosófica subjacente a uma epistemologia e que proporciona um contexto e uma fundamentação para o desenvolvimento de processos de construção do conhecimento, bem como uma base lógica e critérios de validação. É uma forma 
de explicar como conhecemos o que sabemos no âmbito de determinado pensamento filosófico ou de determinada teoria.

Assim, no âmbito da epistemologia da complexidade que fundamenta a obra TerraPátria (MORIN; KERN, 2001,2011), evoca-se, inicialmente, um pensamento ecologizante, capaz de religar os diferentes saberes, as diversas dimensões humanas, mediante o desenvolvimento de um diálogo fecundo entre as várias áreas do conhecimento humano, entre os saberes científicos e humanísticos. Ao promover a ecologia dos saberes e ao reconhecer a sinergia de conhecimentos plurais que dialogam entre si, essa epistemologianos ajuda a perceber as relações ocorrentes que envolvem a cultura, a sociedade, a mente e o indivíduo, indo, portanto, além do ambiente natural, o que favorece a formação de uma consciência de pertencimento mútuo, de nossa inserção em uma mesma comunidade de origem e destino e a emergência de uma consciência ecológica planetária. Reforça também a ideia de que os sistemas educacionais necessitam estar a serviço de uma sociedade sustentável, responsável, solidária e de uma nova ecologia da aprendizagem humana que favoreça a inclusão, a ética da diversidade, do cuidado e da não separatividade.

Ao evocar o pensamento ecologizante, de onde flui todas essas relações, fica fácil perceber que todos esses aspectos são consequências da perspectiva ecológica e relacional, produtora de um saber que emerge das interconexões, das interrelações, dos processos de interdependência e dos intercâmbios entre sujeito/objeto e sujeito/meio.

Esta perspectiva nos informa que a complexidade não foca o conhecimento separado do contexto e dos sujeitos, mas, sim, a partir das relações presentes na dinâmica operacional que envolve todos esses elementos. Isso nos leva a compreender os espaços de aprendizagem, sejam eles virtuais ou presenciais, como sendo um ambiente ecológico, complexo, dinâmico e relacional, no qual vários atores interagem criando redes de interdependência, onde cada parte contribui, à sua maneira, para a construção do todo.

Daí a importância de se conceber os ambientes de aprendizagem como aqueles espaços onde se cultiva uma ecologia libertadora de ideias, de pensamentos, sentimentos e ações. Uma ecologia também preocupada com a reintegração do meio-ambiente à consciência antropológica e social, comprometida com a reforma do pensamento e a abertura do coração.

Mas, para que isso ocorra, a perspectiva dialógica também precisa estar presente nos processos de construção do conhecimento, para dar conta do que é aparentemente antagônico e contraditório. Isso porque, para Edgar Morin, o princípio dialógico constitui a forma operativa do pensamento complexo. É este princípio que favorece a dinâmica operacional que leva à manutenção do triângulo da vida, construído a partir das relações indivíduo/sociedade/natureza, 
como observado na obra Terra-Pátria (MORIN; KERN, 2001,2011). O diálogo é condição estruturante da dinâmica da vida. Ele é o cimento, a base que liga e religa, que sustenta os vínculos entre as pessoas e a sociedade, o indivíduo e a natureza.

Deste diálogo, que permite a articulação desses elementos heterogêneos que se apresentam em diferentes formas de comunicação e de elaboração de significados, revela-se a perspectiva da multirreferencialidade que a epistemologia Terra-Pátria também traz consigo. Ela nos lembra que todo fenômeno, seja educacional ou não, está sujeito a uma pluralidade de enfoques pelo simples fato de ser um campo de confluências de várias ciências, aspectos e dimensões da vida. O plural, constitutivo da realidade, manifesta-se de múltiplas maneiras e todas elas são legítimas e precisam ser consideradas. A multirreferencialidade é também uma abordagem provisória para dar conta dos conhecimentos plurais e da complexidade dos fenômenos.

Outra perspectiva importante, no que se refere ao processo de construção do conhecimento e à aprendizagem decorrentes da epistemologia da complexidade, é a perspectiva transdisciplinar que se ilumina e fecunda a partir dos vários conteúdos disciplinares disponíveis, sinalizando a sua complementaridade e a possibilidade de um conhecer mais global e abrangente envolvendo as diferentes áreas do conhecimento humano. Para Morin (2015), o olhar transdisciplinar, que emerge a partir do uso dos operadores cognitivos para um pensar complexo, facilita a compreensão do mundo atual, ao mesmo tempo em que permite o reencontro com o sujeito transdisciplinar que está "além das disciplinas". Um sujeito multidimensional, portanto, dotado de diferentes dimensões, o que o torna, ao mesmo tempo, um ser cultural, social e espiritual. Esta epistemologia presente no conceito Terra-Pátria exige uma metodologia transdisciplinar que trabalhe essa complexidade da condição humana, ao mesmo tempo em que opera com os conteúdos.

Essa perspectiva transdisciplinar supera a ênfase no conhecimento disciplinar e parcelado a partir de uma racionalidade aberta e complexa que contextualiza o conhecimento e favorece a religação dos saberes, a ecologia dos saberes, levando, portanto, à reforma paradigmática do pensamento e do conhecimento e, certamente, das práticas educacionais. Uma reforma do pensamento e, consequentemente, da ação que se processa ao produzir conhecimentos pertinentes, criativos e contextualizados, colaborando, assim, para a reformulação das bases estruturantes dos processos cognitivos, emocionais e espirituais e, ao mesmo tempo, promovendo o resgate da biopsicossociogênese do conhecimento.

Entendemos, como Morin (2000), que é preciso mudar as bases do raciocínio, sair de uma racionalidade fechada em direção a uma racionalidade aberta que seja capaz de articular, 
de integrar, de sintetizar e analisar, de associar e religar. E, para tanto, é preciso ênfase nas práticas pedagógicas no sentido de complexificá-las, de torná-las abertas e transdisciplinares. Uma epistemologia da complexidade exige uma metodologia transdisciplinar no processo de construção do conhecimento. Uma metodologia que trabalhe a complexidade da condição humana, ao mesmo tempo em que trabalha a complexidade da realidade refletida no conteúdo das diferentes áreas do conhecimento humano.

O conceito Terra-Pátria traz também consigo a perspectiva de solidariedade, alteridade e inclusão, que se materializa na abertura às ideias, imagens e opiniões do outro e numa solidariedade que emerge a partir do momento em que o sujeito percebe que não é possível existir sem a presença do outro, sem compreender e aceitar a legitimidade do outro. Uma solidariedade que não é imposta de fora para dentro, mas que brota no coração de todos aqueles(as)que concebem a vida como processo de evolução coletiva, onde todos somos individualidades em comunhão.

Esta compreensão também nos leva a perceber na dinâmica da vida a perspectiva de coevolução, parceria e religação, indicando que todo sistema complexo não evolui de modo separado, mas junto com o seu entorno, com o seu contexto, do qual está inseparavelmente ligado, energética, informacional e materialmente acoplado. Assim, a evolução humana é sempre relacional, implicada, ecológica e interdependente no seu sentido mais amplo. Fica mais fácil entender que sem cooperação, parceria, solidariedade e amor na maneira de nos relacionarmos uns com os outros, as condições sistêmicas evolutivas dos sistemas vivos vão, aos poucos, se deteriorando.

Desta compreensão flui, necessariamente, uma perspectiva ética. Mas uma ética integrativa que surge iluminada pelos princípios éticos do bem-viver. Uma ética capaz de suportar os riscos em relação ao desconhecido e que está atenta aos desafios das incertezas e emergências, que dialoga com as contradições, diminui a intolerância ao resgatar aqueles valores tradicionais que verdadeiramente fazem sentido para a vida humana(MORIN, 2005).

Tais perspectivas decorrentes da epistemologia da complexidade requerem a ampliação em nossos sistemas de valores, o resgate da ética da diversidade, da responsabilidade, da solidariedade e a percepção de que o bem comum não pertence somente à raça humana, mas a todos os habitantes do planeta Terra, pois tudo que existe merece existir, viver e conviver.

Assim, a epistemologia da complexidade, intrínseca ao conceito Terra-Pátria, traz consigo uma necessária mudança paradigmática da ciência, que nos remete a um novo patamar de consciência mundial que nos ajuda a fundamentar uma nova antropologia, uma axiologia e uma ética planetária que nos levam a compreender que tanto os seres humanos como a natureza 
possuem uma origem e um destino comum. Daí a necessidade de ampliar os nossos sistemas de valores, de cultivar uma ética capaz de sustentar um novo modelo civilizatório de sociedade, de ser humano e de conhecimento. Todos esses aspectos indicam que precisamos aprender a educar a sensibilidade do ser aprendente, a cultivar a ética da solidariedade cósmica que ilumina nossa capacidade de viver/conviver em busca de novos horizontes civilizatórios que abram espaços para a esperança e o bem-viver/conviver.

Sem esta mudança paradigmática no tipo de racionalidade, que todavia predomina em nossas abordagens pedagógicas, fica difícil, ou mesmo quase impossível, promover essa almejada mudança. Ela necessariamente precisa estar fundada na construção de um pensamento ecologizado, de um pensamento de religação e em processos de formação integral de natureza transdisciplinar e, se possível, também associada aos processos emancipatórios e problematizadores propostos por Paulo Freire.

\section{Considerações finais e provisórias: Terra-Pátria e a Pedagogia da Esperança}

Então, como fazer para que o conceito Terra-Pátria e sua epistemologia da complexidade assumam um caráter pedagógico? Ou que as grandes questões pedagógicas se interliguem com as perspectivas filosóficas e científicas que nutrem este conceito?

Primeiramente, é preciso entender que a consciência ecológica e planetária não floresce a partir de um pensamento tradicional, linear, disjuntivo e simplificador. Ela resulta de novas formas de pensar e de compreender a realidade, o que pressupõe uma visão complexa e transdisciplinar que transcenda as barreiras disciplinares e privilegie o sujeito e, ao mesmo tempo, destaca aquilo que é relacional, dialógico e interdependente no que se refere ao conhecimento e à aprendizagem.

Pedagogicamente, trabalha-se com uma racionalidade aberta, usando os operadores cognitivos para um pensar complexo e transdisciplinar, integrando, articulando, associando e religando os diferentes conteúdos disponibilizados, na tentativa de superar o reducionismo e a simplificação dos processos pedagógicos tradicionais. Este tipo de racionalidade aberta favorece, necessariamente, o diálogo com a realidade e o processo de conscientização do sujeito aprendente, ajuda no trabalho analítico, dialógico, a desenvolver a reflexão sobre a prática, a dialogar com os erros e os acertos presentes nas ações desenvolvidas.

Assim, os operadores cognitivos são mecanismos geradores dessa epistemologia para o desenvolvimento do pensamento, para a construção do conhecimento e melhor compreensão da realidade. Aplicados na prática pedagógica, eles tornam possível a comunicação entre os 
sujeitos, entre o sujeito e a sua realidade, catalisando processos de mudança consciencial. É o diálogo, nutrido pela reflexão que lhe está subjacente, que promove a transição da consciência ingênua para a consciência crítica, do pensamento mágico para um pensamento crítico e mais global a respeito da realidade social e cultural. E quanto mais evolui em sua criticidade, mais evolui em sua capacidade de dialogar com a realidade, de se auto-eco-organizar em relação a ela e de transformar a si mesmo e o mundo ao seu redor.

Metodologicamente falando, recomendamos a realização do trabalho pedagógico com os operadores cognitivos, tendo como referência um duplo compromisso. Inicialmente, um compromisso que trabalha no âmbito do SER, ao transformar suas condições cognitivas, emocionais, psicológicas, culturais e espirituais que promovem o seu desenvolvimento humano, e outro que atue no âmbito do ESTAR ajudando o aprendiz a superar as condições materiais de sua existência que impedem seu pleno desenvolvimento e a melhorar sua qualidade de vida.

Desta forma, procura-se trabalhar pedagogicamente os conteúdos de maneira transdisciplinar, tendo como foco o SER e o ESTAR. Isso é possível quando os conteúdos dialogam com a vida, com o contexto, com o cotidiano para que o conhecimento a ser construído seja significativo e pertinente.

É aqui que podemos estabelecer também a ponte entre a epistemologia Terra-Pátria e a Pedagogia da Esperança proposta por Paulo Freire (2014) e perceber o quanto elas se enriquecem mutuamente, lembrando que o princípio dialógico é a forma operativa do pensamento complexo, da mesma forma que Paulo Freire também o considerava como uma categoria ontológica, epistemológica, metodológica e antropológica de sua pedagogia. Ou seja, o diálogo é condição existencial e está na base da relação epistemológica sujeito/objeto e sujeito/realidade, como instrumento de escuta e intervenção pedagógica. É, portanto, condição para a materialização de sua metodologia, pautada nos processos de reflexão/ação, e nas relações teoria/prática, sujeito/contexto e educador/educando. É antropológica porque através dele nos construímos como pessoas.

Para Paulo Freire, é a consciência crítica que instrumentaliza o fazer histórico do sujeito. Para Edgar Morin, ela é sempre relacional e, portanto, de natureza complexa.

Para se chegar à consciência crítica, o sujeito trabalha com os operadores cognitivos para um pensar complexo, na tentativa de superar a consciência ingênua, vivenciando um processo de conscientização de natureza transdisciplinar. Deste movimento com os operadores emerge uma nova consciência crítica que, por sua vez, vem acompanhada por uma nova sensibilidade, por uma nova capacidade de escuta, de diálogo, de compreensão a respeito da realidade, do sentido da vida e do significado da existência. Ao vivenciar tal processo, o sujeito 
se fortalece, transforma-se em autor de sua própria história, resgata sua autoestima, liberta-se da opressão.

Sob o nosso ponto de vista, a consciência crítica corresponde ao estado transdisciplinar, que se manifesta em um nível de realidade superior, a partir de processos dialógicos problematizadores em relação aos acontecimentos, aos fatos e aos eventos que estão sendo processados. Para Freire(2015, 2014, 1987), é o conflito cognitivo decorrente da problematização, que leva ao estabelecimento de situações-limite, nas quais o velho conhecimento já não se sustenta e de onde surge o inédito-viável, que traz consigo novas possibilidades de solução aos problemas emergentes. O diálogo com as situações-limite, do qual surge o inédito-viável, constitui, na prática, o exercício de uma lógica de natureza transdisciplinar e que se manifesta em um outro nível de realidade, sendo percebido e compreendido a partir da expansão do nível de percepção e de consciência do sujeito aprendente.

Entendemos que a superação da opressão implica um pensamento complexo nutrido pelos operadores cognitivos e uma atitude transdisciplinar por parte do sujeito oprimido. A busca por uma terceira via ainda não descoberta, ou seja, o desenvolvimento de um processo de conscientização dirigido a enfrentar as situações de opressão e a favorecer o compromisso social e político para a transformação dessas situações, demanda atitudes transdisciplinares para que sua libertação aconteça. Assim, do caos, da desordem cognitiva e emocional, é possível se chegar a uma nova ordem que se apresenta como o inédito-viável e que somente acontece a partir de uma prática libertadora de natureza complexa e transdisciplinar.

\section{Referências}

BRASIL. A Carta da Terra em Ação. Disponível em:http://www.cartadaterrabrasil.com.br/prt/texto-da-carta-da-terra.html.Acesso em: 22 abr. 2021a.

BRASIL Plataforma Agenda2030.Disponível em: http://www.agenda2030.com.br/.Acesso em: 24 abr. $2021 b$.

BUNGE, M. Epistemologia: curso de atualização. Tradução de Claudio Navarro. São Paulo: Editora da Universidade de São Paulo, 1980.

BUNGE, M. Epistemologia.Buenos Aires: Siglo Veintiuno Editores, 1977.

FREIRE, P. Ação cultural para a liberdade e outros escritos.15. ed. Rio de Janeiro: Paz e Terra, 2015. 
FREIRE, P. Pedagogia da esperança: um reencontro com a pedagogia do oprimido. 21. ed. São Paulo: Paz e Terra, 2014.

FREIRE, P. Pedagogia do oprimido. 17. ed. Rio de Janeiro: Paz e Terra, 1987.

MORIN, E. A aventura de O Método e Para uma racionalidade aberta. Tradução de Edgard de Assis Carvalho e Mariza Perassi Bosco. São Paulo: Edições Sesc São Paulo, 2020.

MORIN, E. A cabeça bem-feita: repensar a reforma, reformar o pensamento. Tradução de Eloá Jacobina. Rio de Janeiro: Bertrand Brasil, 2000.

MORIN, E. Ensinar a viver: manifesto para mudar a educação. Tradução de Edgard de Assis Carvalho e Mariza Perassi Bosco. Porto Alegre: Sulina, 2015.

MORIN, E. $O$ método 2: a vida da vida. Tradução de Marina Lobo. 4.ed. Porto Alegre: Sulina, 2011.

MORIN, E. O método 6: ética. Tradução de Juremir Machado da Silva. Porto Alegre: Sulina, 2005.

MORIN, E.; KERN, A. B. Terra-Pátria. Tradução de Armando Pereira da Silva. 2. ed. Lisboa: Instituto Piaget, 2001.

MORIN, E. Terra-Pátria. Tradução de Paulo Neves da Silva. 6. ed. Porto Alegre: Sulina,2011.

MORIN, E.; LE MOIGNE, J-L. A inteligência da complexidade. Tradução de Nurimar Maria Falci. São Paulo: Peirópolis, 2000.

VON GLASERSFELD, E. Introdução ao construtivismo radical. In: WATZLAWICK, P. (org.). A Realidade Inventada. Campinas: Editorial Psy, 1994. p. 24-45. 